Ärztliche Erfahrung beschränkt sich nicht auf medizinisches Fachwissen.

Sie entsteht auch aus den mehr oder minder alltäglichen, heiter,

\title{
Schnitzeljagd nach der verlorenen Patientin
}

_ Am Nachmittag flatterte mir per Fax ein $\mathrm{Hb}$-Wert von $6,0 \mathrm{~g} / \mathrm{dl}$ in mein Sprechzimmer. Die zugehörige Patientin hatte ich zuvor wegen Müdigkeit und Leistungsschwäche untersucht. Alarmiert versuchte ich, sie telefonisch

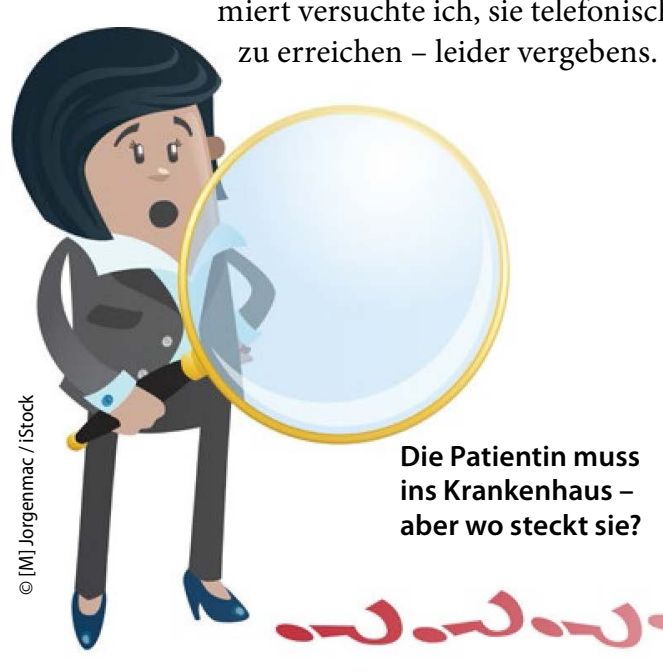

Kurzerhand beschloss ich, sie nach der Sprechstunde zu Hause zu besuchen, um sie sofort ins Krankenhaus einzuweisen. Jedoch traf ich sie auch in ihrer Wohnung nicht an. Ich hinterließ ihr also einen Zettel im Briefkasten, auf dem ich sie bat, dringend in die Praxis zu kommen. Ganz wohl war mir bei der Sache aber immer noch nicht, da die Patientin Analphabetin war und ich nicht sicher sein konnte, dass jemand ihr die Nachricht vorlesen würde.

Da fiel mir ein, dass die Patientin mit Frau B. befreundet war. Schnurstracks fuhr ich zu deren Wohnung am anderen Ende des Viertels. Frau B. kam gerade vom Einkaufen um die Ecke. Meine Patientin, so versicherte sie mir, sei eigentlich nie zu Hause. „Meistens ist die bei meinem Bruder - da können wir ja eben hinfahren", bot sie an.

Gesagt, getan. Doch auch der Bruder war nicht zu Hause. Jetzt fiel Frau B. ein, dass die Patientin ja oft Herrn S. im Haushalt helfe. Dort fuhren wir als nächstes hin. Herr S., ebenfalls einer meiner Patienten, freute sich, mich $\mathrm{zu}$ sehen, hatte die Patientin an diesem Tag aber noch nicht gesehen. Er versprach auszurichten, dass sie sich bei mir melden sollte. So fuhr ich schließlich nach Hause - unverrichteter Dinge, aber mit dem Gefühl, alles gegeben zu haben.

Punkt 8 Uhr am nächsten Morgen stand meine Patientin in der Praxis. Sie ging noch am selben Tag ins Krankenhaus.

Gabriela Piras, Duisburg

\section{Ein Federvieh als polyglotte Abnehmhilfe}

_ Mit manchen Patienten darf man sich ja durchaus mal einen Spaß erlauben. Vor allem, wenn man die Fopperei mit einer kleinen Gesundheitslektion verbinden kann - das kommt dem Patienten ja unterm Strich zugute, und der Arzt muss kein übermäßig schlechtes Gewissen haben.

Einen meiner Lieblingsscherze probierte ich neulich bei einem Studenten aus Abuja aus, der sich mit seinen $102 \mathrm{~kg}$ $\mathrm{zu}$ dick fand und deswegen meinen Rat suchte. „Dann müssen Sie erst mal ein Uhu werden“, riet ich ihm. Ich erwartete natürlich eine Rückfrage. Doch er sagte nur „Ja“ zur Antwort, was mich wiederum verblüffte, da er überhaupt nicht wissen konnte, was ich meinte. „Wissen Sie, was ein Uhu ist?“, fragte ich zweifelnd. „Ja, ein Klebstoff“, sagte der höfliche Student. „Stimmt“, meinte ich, auch wenn ich anderes im Sinn hatte.

Der Uhu ist das Wappentier unseres kleinen Stadtzoos - und mein Wappen- tier für alle Patienten, die ihr Gewicht $\mathrm{U}$ (nter) $\mathrm{Hu}$ (ndert) bringen möchten. Ich schickte den Studenten in den Zoo und forderte ihn auf, den Uhu mit „Uuuhuuu“ anzusprechen.

Zur Antwort bekam er tatsächlich ein „Uuuuhuuuu“. Nun weiß ich also auch, dass unser Wappentier die nigerianische Sprache Yaruba versteht. Uhus sind eben schlau. Ach ja, der Student kam kurz darauf mit $99 \mathrm{~kg}$ in die Praxis.

Dr. Luise Hess, Darmstadt 